\title{
Changing Provider PSA Screening Behavior Using Best Practice Advisories: Interventional Study in a Multispecialty Group Practice
}

\author{
Joseph Presti Jr, MD ${ }^{1,2}$ (1) Stacey Alexeeff, $\mathrm{PhD}^{2}$, Brandon Horton, $\mathrm{MPH}^{2}$, \\ Stephanie Prausnitz, $M S^{2}$, and Andrew L. Avins, MD, $\mathrm{MPH}^{2,3}$
}

\begin{abstract}
'Department of Urology, Kaiser Permanente Northern California, Oakland, CA, USA; ${ }^{2}$ Division of Research, Kaiser Permanente Northern California, Oakland, CA, USA; ${ }^{3}$ Department of Medicine, Kaiser Permanente Northern California, Oakland, CA, USA.
\end{abstract}

BACKGROUND: Most guidelines recommend against PSA-based screening for prostate cancer in men $\geq 70$ years of age. Adherence to these guidelines is variable.

OBJECTIVE: To determine whether the use of a "Best Practice Advisory" (BPA) intervention within the electronic medical record (EMR) system can alter the rate of PSA screening in men $\geq 70$ years of age.

DESIGN: This is an interventional study spanning the years 2013 through 2017, in men $\geq 70$ years of age in Kaiser Permanente Northern California with no prior history of prostate cancer. The BPA intervention was activated in the EMR system on October 15, 2015, with no prior notice or education.

SETTING: Integrated healthcare system including all Kaiser Permanente Northern California facilities.

PARTICIPANTS: A population-based sample that included all male members $\geq 70$ years of age without a history of prostate cancer.

MAIN MEASURES: The main outcome was the rate of PSA testing in men $\geq 70$ years of age. We compared the rates of PSA testing between the pre-BPA period (January 1, 2013-October 14,2015) and the post-BPA period (October 15, 2015-December 31, 2017). An interrupted time series analysis of PSA ordering rates was performed. KEY RESULTS: Following the 2015 BPA intervention, screening rates substantially declined from 36.0 per 100 person-years to 14.9 per 100 person-years (rate ratio = 0.415; 95\% CI: 0.410-0.419). The effect of the BPA was comparable among all patient races and ordering provider specialties. The interrupted time series analysis showed a rapid, large, and sustained drop in the rate of PSA ordering, and much less temporal variation in test ordering after activation of the BPA.

CONCLUSION: Following activation of a BPA within the EMR, the rates of inappropriate PSA testing significantly declined by $58.5 \%$ in men $\geq 70$ years of age and temporal variation was reduced.

KEY WORDS: screening; prostate cancer; PSA

Prior Presentations American Urological Association Annual Meeting, May 4, 2019

Received August 9, 2019

Accepted July 30, 2020

Published online October 26, 2020
J Gen Intern Med 35(Suppl 2):S796-S801

DOI: $10.1007 / \mathrm{s} 11606-020-06097-2$

(c) Society of General Internal Medicine 2020

\section{INTRODUCTION}

In the past several years, the American College of Physicians, the American Academy of Family Physicians, the United States Preventive Services Task Force, and the American Urological Association have recommended against prostate cancer screening in men 70 years of age and older. ${ }^{1-4}$ This differs from the shared decision-making process that these organizations recommend for prostate-specific antigen (PSA)-based prostate cancer screening in men under age 70 . No randomized screening trial shows benefit of screening men 70 years of age or older and the risks of overdiagnosis and thus overtreatment are significant in this population. ${ }^{5}$

Despite the consensus that routine screening in this population is not indicated, inappropriate prostate cancer screening is common among older men. Estimates from the European Randomized Study of Screening for Prostate Cancer (ERSPC) suggest overdetection (detection of indolent cancers not requiring treatment) rates in men 70 years of age and older to be greater than 50\%. ${ }^{6}$ The Healthcare Effectiveness Data and Information Set (HEDIS) has a specific "overuse/appropriateness" measure pertinent to this population, specifically "Nonrecommended PSA-based screening in older men" defined as men 70 years of age and older. However, national adherence with this HEDIS measure is generally low, with screening rates of men 70 years of age and older reported to be between 31.0 and $34.5 \%$ in the years 2015 to $2017 .^{7}$ Furthermore, minimal data exist on effective strategies for reducing this practice of over screening.

A growing body of data suggests that alerts or advisories within the electronic medical record (EMR) system can increase safety and efficiency in clinical care. Some alerts notify providers of patient allergies or recommend medication dose adjustments in hepatic or renal insufficiency. Other alerts promote appropriate test ordering or prevent inappropriate repetitive test ordering. 


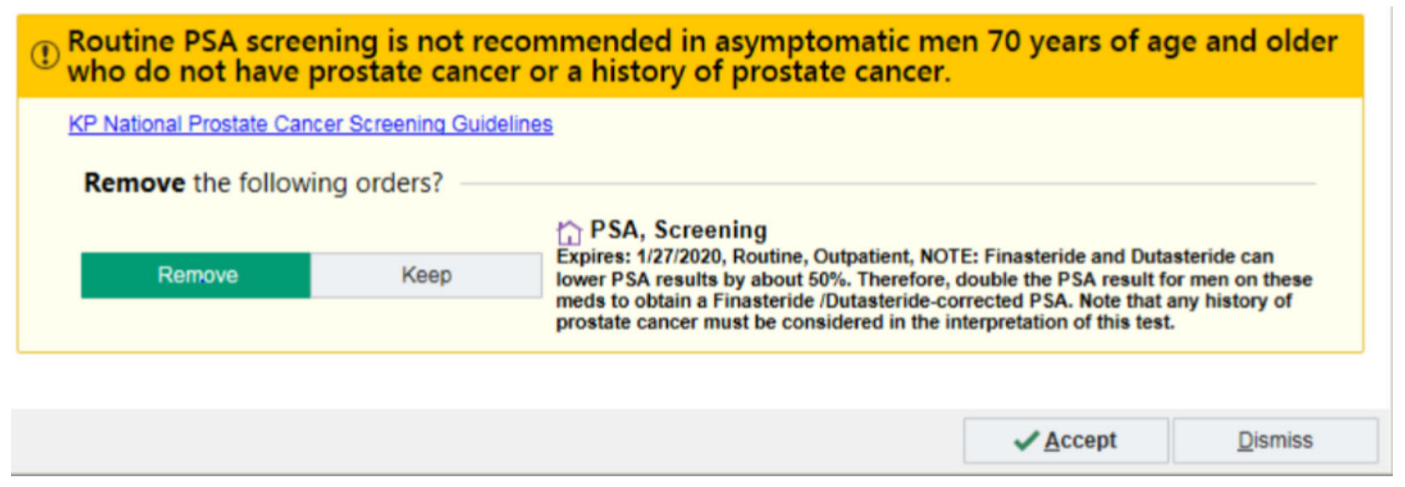

Figure 1 Best Practice Advisory which providers saw in the electronic medical record if they tried to order a PSA test in a man 70 years of age or older with no history of prostate cancer.

Two studies have been reported that utilized the EMR to regulate PSA testing. One looked at repetitive PSA testing in men of all ages and did not find a statistically significant effect. ${ }^{8}$ Another, using a strategy similar to ours, used a "Best Practice Advisory" (BPA) in a single Veterans Affairs Hospital to decrease PSA ordering in men 75 years of age and older, and did demonstrate a significant decline in testing. ${ }^{9}$

We focused on leveraging the EMR to improve adherence to a quality indicator that recommends against PSA screening in men 70 years of age and older in a large integrated healthcare system. We implemented an intervention using a BPA within the EMR throughout Kaiser Permanente Northern California (KPNC), with a goal to reduce the rates of inappropriate PSA testing in men 70 years of age and older with no history of prostate cancer. This study evaluates the effectiveness of our intervention by quantifying the rates of PSA testing in this population before and after implementation of our intervention.

\section{METHODS}

\section{Study Population}

KPNC is a large integrated healthcare system that includes 21 hospitals, 247 medical offices, and over 9000 physicians that provides comprehensive medical services to over 4 million members in Northern California. The study population for this intervention study included all men $\geq 70$ years of age with no prior history of prostate cancer who were members of KPNC at any time during 2013 through 2017.

\section{Intervention}

The BPA intervention was activated in our electronic medical record system at all medical centers on October 15, 2015. No additional interventions were used (i.e., there were no warnings, emails, or educational interventions accompanying the introduction of the BPA). The BPA appeared on the EMR screen if a provider attempted to order a PSA test in a man $\geq 70$ years of age with no history of prostate cancer documented in our EMR (Fig. 1). The specific ICD9 and ICD10 codes, which if present in the EMR, would prevent the appearance of the BPA included: 185, 199.1, V10.46, V45.77, V15.3, V10.46, V15.3, C61, C79.9, Z85.46, Z90.79, Z92.3, Z85.46. Providers could override and complete the order with an additional "click" if desired (e.g., patient with possible symptoms related to prostate cancer or patient preference). The BPA also provided a hyperlink to the Kaiser Permanente National Prostate Cancer Screening Guideline which provides an evidence-based approach to PSA screening (and that recommends against screening in men at least 70 years old).

\section{Outcomes}

The outcome studied was the rate of PSA testing in men at least 70 years old both before and after the intervention of the BPA.

Table 1 Study Population

\begin{tabular}{|c|c|c|c|c|c|c|}
\hline \multirow[t]{2}{*}{ Year } & \multicolumn{2}{|c|}{$\begin{array}{l}\text { Men } \geq 70 \\
\text { No history of prostate } \\
\text { cancer }\end{array}$} & \multicolumn{4}{|c|}{$\begin{array}{l}\text { PSA screened men } \geq 70 \\
\text { No history of prostate cancer }\end{array}$} \\
\hline & $N$ & $\begin{array}{l}\text { Age, median } \\
\text { (IQR) (years) }\end{array}$ & $N(\%)$ & Age, median (IQR) (years) & PSA median (IQR) (ng/ml) & $\begin{array}{l}\text { PSA screen rate and 95\% } \\
\text { CI (per } 100 \text { person-years) }\end{array}$ \\
\hline $\begin{array}{l}2013 \\
2014 \\
2015 \\
2016 \\
2017\end{array}$ & $\begin{array}{l}129,530 \\
135,404 \\
141,998 \\
150,208 \\
160,259\end{array}$ & $\begin{array}{l}75(72-81) \\
75(71-81) \\
75(72-81) \\
75(71-81) \\
75(71-80)\end{array}$ & $\begin{array}{l}39,118(30.2) \\
36,632(27.1) \\
32,635(23.0) \\
18,251(12.2) \\
17,997(11.2)\end{array}$ & $\begin{array}{l}74(71-77) \\
73(71-77) \\
73(71-77) \\
73(71-77) \\
73(71-76)\end{array}$ & $\begin{array}{l}2.7(1.2-5.7) \\
2.1(0.9-4.5) \\
2.1(0.9-4.5) \\
2.5(1.0-5.4) \\
2.4(1.0-5.5)\end{array}$ & $\begin{array}{l}41.4(41.1-41.8) \\
34.6(34.3-34.9) \\
29.0(28.7-29.3) \\
15.6(15.4-15.8) \\
14.4(14.2-14.6)\end{array}$ \\
\hline
\end{tabular}


Table 2 Annual Numbers and Percentages of Men "At Risk" for PSA Testing

\begin{tabular}{|c|c|c|c|c|c|c|}
\hline \multirow[t]{2}{*}{ Year } & \multicolumn{6}{|l|}{ Race } \\
\hline & $\begin{array}{l}\text { Caucasian } \\
N(\%)^{*}\end{array}$ & $\begin{array}{l}\text { Asian } \\
N(\%)^{*}\end{array}$ & $\begin{array}{l}\text { African American } \\
N(\%)^{*}\end{array}$ & $\begin{array}{l}\text { American Indian } \\
N(\%)^{*}\end{array}$ & $\begin{array}{l}\text { Pacific Islander } \\
N(\%)^{*}\end{array}$ & $\begin{array}{l}\text { Unknown } \\
N(\%)^{*}\end{array}$ \\
\hline 2013 & $94,951(73.3 \%)$ & $18,226(14.1 \%)$ & $7124(5.5 \%)$ & $682(0.5 \%)$ & $639(0.5 \%)$ & $7908(6.1 \%)$ \\
\hline 2014 & $98,250(72.5 \%)$ & $19,478(14.4 \%)$ & $7322(5.4 \%)$ & $747(0.5 \%)$ & $702(0.5 \%)$ & $8905(6.6 \%)$ \\
\hline 2015 & $101,890(71.8 \%)$ & $20,843(14.7 \%)$ & $7559(5.3 \%)$ & $793(0.6 \%)$ & $780(0.5 \%)$ & $10,133(7.1 \%)$ \\
\hline 2016 & $106,583(71.0 \%)$ & $22,506(15.0 \%)$ & $7900(5.3 \%)$ & $848(0.5 \%)$ & $852(0.5 \%)$ & $11,519(7.7 \%)$ \\
\hline 2017 & $112,555(70.2 \%)$ & $24,540(15.3 \%)$ & $8312(5.2 \%)$ & $913(0.6 \%)$ & $916(0.6 \%)$ & $13,023(8.1 \%)$ \\
\hline
\end{tabular}

*Numbers and percentages of men "at risk" for PSA testing that year

\section{Statistical Analysis}

We a priori identified two time periods: the "before intervention period" (January 1, 2013, to October 14, 2015) and the "after intervention period" (October 15, 2015, to December 31, 2017).

We computed the rate of PSA testing in men at least 70 years old annually from 2013 to 2017 and during the period before and after the intervention. All eligible men within a given year were included in the denominator in all rate calculations accounting for the duration of enrollment within that year (person-years at risk). A rate ratio (RR) and 95\% confidence interval $(\mathrm{CI})$ were calculated to compare the rates of men tested between the two time periods. We conducted an interrupted time series (ITS) analysis to evaluate introducing the BPA as a population-level intervention and its effect on this rate. ${ }^{10}$ Two-sided $p$ values $<0.05$ were considered statistically significant. Analyses were conducted in SAS 9.3 and R 3.4.4.

\section{RESULTS}

Table 1 shows the characteristics of our study population and the annual PSA testing rates among individual men 70 years of age and older with no history of prostate cancer. Prior to our intervention, the PSA testing rate was 36.0 per 100 personyears (95\% CI: 35.9-36.2). After the intervention, this rate declined to 14.9 per 100 person-years (95\% CI: 14.8-15.1). The rate ratio was 0.415 (95\% CI: $0.410-0.419$ ).

Tables 2 and 3 show the entire study population and those who underwent PSA testing, respectively, stratified by race. Table 2 shows the "at risk population," specifically men 70 years of age and older with no history of prostate cancer. There was no significant change in the racial composition of the population over the study period. Table 3 shows the men who underwent PSA testing stratified by race. The frequency of testing was comparable in all races both prior to and after our BPA.

Table 4 shows the ordering provider specialty. Approximately three-quarters of the PSA testing was ordered by primary care (internal medicine and family practice). The relative contribution of the various specialties to PSA testing did not significantly vary over the study period.

Interrupted time series analysis models the trend in the rate over time before and after the intervention and tests whether a statistically significant change in the rate trend occurred after the intervention. The results of our ITS analysis (Fig. 2) show a declining slope prior to the activation of the BPA with substantial temporal variation. After activation of the BPA, we observed a rapid, substantial, and sustained drop in the rate (i.e., level change) as well as a change to a near horizontal slope; both the level and slope changes were statistically significant $(p<0.001)$. In addition, the month-to-month variation in rates, as measured by the overdispersion of the Poisson model was estimated to be 3.7 times larger before the intervention as compared with after the intervention, which was statistically significant $(p<0.001)$.

\section{DISCUSSION}

In a study of electronic medical records in men 70 years of age and older cared for in a large, diverse, community-based healthcare system, we found that relative inappropriate screening rates declined $58.5 \%$ following a simple intervention in the EMR. The effect of the BPA was comparable among all patient races as well as across different provider specialties. It is important to recognize that our healthcare system spans a

Table 3 Annual Numbers and Percentages of Men "At Risk" Who Underwent PSA Testing

\begin{tabular}{|c|c|c|c|c|c|c|}
\hline \multirow[t]{2}{*}{ Year } & \multicolumn{6}{|l|}{ Race } \\
\hline & $\begin{array}{l}\text { Caucasian } \\
N(\%)^{*}\end{array}$ & $\begin{array}{l}\text { Asian } \\
N(\%) *\end{array}$ & $\begin{array}{l}\text { African American } \\
N(\%)^{*}\end{array}$ & $\begin{array}{l}\text { American Indian } \\
N(\%)^{*}\end{array}$ & $\begin{array}{l}\text { Pacific Islander } \\
N(\%)^{*}\end{array}$ & $\begin{array}{l}\text { Unknown } \\
N(\%)^{*}\end{array}$ \\
\hline 2013 & $28,337(29.8 \%)$ & $6037(33.1 \%)$ & $2063(29.0 \%)$ & $204(29.9 \%)$ & $180(28.2 \%)$ & $2297(29.0 \%)$ \\
\hline 2014 & $26,262(22.7 \%)$ & $5828(29.9 \%)$ & $1837(25.1 \%)$ & $222(29.7 \%)$ & $183(26.1 \%)$ & $2300(25.8 \%)$ \\
\hline 2015 & $23,403(23.0 \%)$ & $5174(24.8 \%)$ & $1575(20.8 \%)$ & $188(23.7 \%)$ & $161(20.6 \%)$ & $2134(21.1 \%)$ \\
\hline 2016 & $13,398(12.6 \%)$ & $2563(11.4 \%)$ & $941(11.9 \%)$ & $96(11.3 \%)$ & $90(10.6 \%)$ & $1163(10.1 \%)$ \\
\hline 2017 & $13,097(11.6 \%)$ & $2567(10.5 \%)$ & $950(11.4 \%)$ & $103(11.3 \%)$ & $89(9.7 \%)$ & $1191(9.1 \%)$ \\
\hline
\end{tabular}

*Numbers and percentages of "at risk" population undergoing PSA testing that year 
large geographic area and has 21 major medical centers and 247 medical offices and employs more than 4000 primary care providers. On October 15, 2015, the BPA was activated in our EMR at all medical centers throughout our organization. This was an isolated intervention, without any antecedent provider education or structured promotion; therefore, the cost of implementation was very small (primarily a small amount of EMR programmer time). If providers attempted to order a PSA test in a man 70 years of age or older, with no history of prostate cancer, a warning appeared on the screen stating "Routine PSA screening is not recommended in asymptomatic men 70 years of age and older who do not have prostate cancer or history of prostate cancer." An override was available because in a small number of select patients-for example, those presenting with signs or symptoms suggestive of prostate cancer-testing is appropriate and our intention was to provide primary care providers with maximal decisionmaking authority and flexibility. Prior to implementation of the BPA, our inappropriate screening rate (36 per 100 personyears) in this population was similar to what is reported at the HEDIS website with national rates ranging from 31.0 to $34.5 \%$ in $2015-2017 .^{7}$ Following activation of the BPA, a rapid, large, and durable decline was observed in our system and temporal variation was substantially reduced, as seen in the ITS analysis (Fig. 2). It should be noted that even prior to activation of the BPA, screening rates were declining in this population. We suspect this may have been due to the 2012 United States Preventive Services Task Force (USPSTF) statement which gave a "D" grade ("Discourage the use of this service") to PSA-based screening for prostate cancer in all age groups. ${ }^{11}$ While overall temporal trends showed a gradual decline in inappropriate test ordering over the observation period, there was a rapid, large, and sustained drop in guideline-discordant test ordering after the BPA was deployed.

Inappropriate testing in this population has large implications. With respect to the direct financial burden of the PSA blood test alone, Medicare Part B payment for a PSA test was

Table 4 Annual Numbers and Percentages of Ordering Provider Specialty

\begin{tabular}{|c|c|c|c|c|c|}
\hline \multirow[t]{2}{*}{ Year } & \multicolumn{5}{|l|}{ Specialty } \\
\hline & $\begin{array}{l}\text { Internal } \\
\text { medicine } \\
N(\%)^{*}\end{array}$ & $\begin{array}{l}\text { Family } \\
\text { practice } \\
N(\%)^{*}\end{array}$ & $\begin{array}{l}\text { Urology } \\
N(\%)^{*}\end{array}$ & $\begin{array}{l}\text { Other }^{\dagger} \\
N(\%)^{*}\end{array}$ & $\begin{array}{l}\text { Unknown } \\
N(\%)^{*}\end{array}$ \\
\hline 2013 & $\begin{array}{l}24,521 \\
(49.6 \%)\end{array}$ & $\begin{array}{l}11,780 \\
(23.8 \%)\end{array}$ & $\begin{array}{l}8077 \\
(16.3 \%)\end{array}$ & $\begin{array}{l}4116 \\
(8.3 \%)\end{array}$ & $\begin{array}{l}995 \\
(2.0 \%)\end{array}$ \\
\hline 2014 & $\begin{array}{l}22,272 \\
(51.4 \%)\end{array}$ & $\begin{array}{l}11,111 \\
(25.7 \%)\end{array}$ & $\begin{array}{l}5896 \\
(13.6 \%)\end{array}$ & $\begin{array}{l}3006 \\
(6.9 \%)\end{array}$ & $\begin{array}{l}1035 \\
(2.4 \%)\end{array}$ \\
\hline 2015 & $\begin{array}{l}19,271 \\
(50.6 \%)\end{array}$ & $\begin{array}{l}10,454 \\
(27.4 \%)\end{array}$ & $\begin{array}{l}4947 \\
(13.0 \%)\end{array}$ & $\begin{array}{l}2468 \\
(6.5 \%)\end{array}$ & $\begin{array}{l}975 \\
(2.5 \%)\end{array}$ \\
\hline 2016 & $\begin{array}{l}9118 \\
(42.5 \%)\end{array}$ & $\begin{array}{l}5837 \\
(27.2 \%)\end{array}$ & $\begin{array}{l}4200 \\
(19.6 \%)\end{array}$ & $\begin{array}{l}1735 \\
(8.1 \%)\end{array}$ & $\begin{array}{l}579 \\
(2.6 \%)\end{array}$ \\
\hline 2017 & $\begin{array}{l}9073 \\
(42.9 \%)\end{array}$ & $\begin{array}{l}6292 \\
(29.6 \%)\end{array}$ & $\begin{array}{l}3677 \\
(17.4 \%)\end{array}$ & $\begin{array}{l}1817 \\
(8.6 \%)\end{array}$ & $\begin{array}{l}311 \\
(1.5 \%)\end{array}$ \\
\hline
\end{tabular}

*Numbers and percentages of tests ordered that year by specialty in the study population

fIncludes other medical specialties and nurse practitioners
$\$ 25.23$ in $2017 .{ }^{12}$ Nationwide in 2017 , approximately 4.3 million tests were ordered in the Medicare population age $(\geq$ 65 years of age) and Medicare payments were $\$ 105,000,000$ (while this study does not report on testing in men specifically over the age of 69 , national HEDIS data confirms a large number of these tests were in men 70 years of age and older). In addition to the actual blood tests, elevated PSA test results often lead to additional diagnostic tests including a prostate biopsy and downstream intervention costs. For 2018, global Medicare reimbursement for a prostate biopsy was $\$ 434 .{ }^{13}$ Patients who are found to have cancer will often undergo additional diagnostic imaging such as CT or MRI scans and bone scans. Finally, some of these men with cancer will undergo treatment such as surgery or radiation therapy which results in additional costs and subjects patients to quality of life-related risks pertaining to bowel, bladder, and sexual function.

Population-based interventions have been shown to result in more appropriate laboratory utilization for many tests including erythrocyte sedimentation rates, microscopic urinalyses, renal and thyroid function tests, and iron stores. ${ }^{14}$ Typically, these interventions have involved changes in guidelines, funding policies, or laboratory ordering forms. The EMR provides a unique opportunity to interact with providers and influence ordering behavior in real time. Well-established examples are in the areas of drug-drug interaction warnings or drug allergy alert warnings within the EMR. ${ }^{15}$ Less information is available regarding leveraging the EMR to influence test ordering. Providing laboratory costs at the time of order entry resulted in a decline in test ordering in one study. ${ }^{16}$ The use of a BPA for repetitive ordering has been shown to be successful for laboratory tests in the ICU setting. ${ }^{17}$ A clusterrandomized trial using a BPA demonstrated a safe reduction in

\section{Rate of PSA testing among age $70+$ by month}

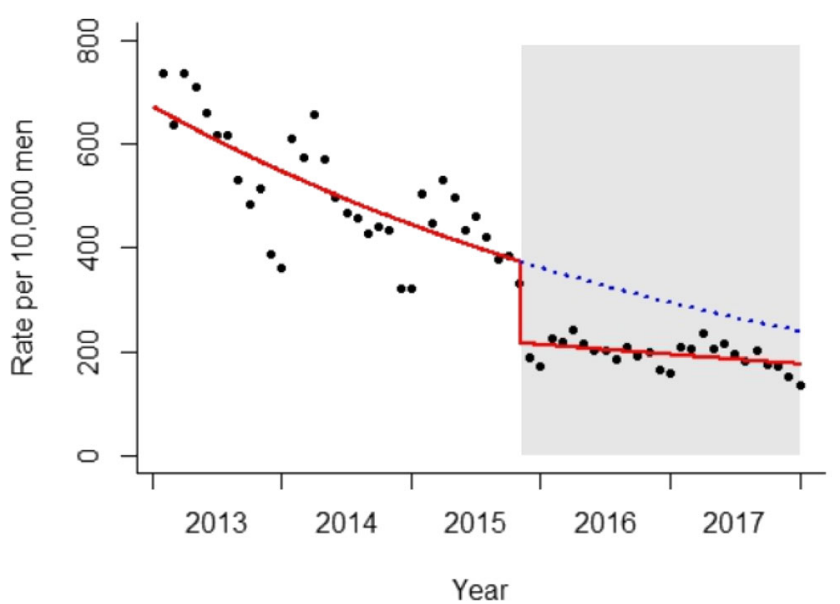

Figure 2 Interrupted time series analysis. Notice PSA ordering rates were declining yet had large temporal variation prior to the activation of the Best Practice Advisory (BPA). Following activation of the BPA on October 15, 2015, PSA ordering rates were substantially and significantly lower and temporal variation was reduced. The dotted line in the shaded area is an estimate if the downward trend persisted. 
telemetry duration in the inpatient setting. ${ }^{18}$

As mentioned previously, one study evaluated the use of a BPA to reduce repetitive PSA testing in patients of all ages. ${ }^{8}$ This study used an alert within the EMR to avoid repetitive testing and did have a significant impact on several tests including sedimentation rate, lipid panels, thyroidstimulating hormone, and vitamin D but had a nonsignificant effect on PSA (OR $=0.74,95 \%$ CI 0.24-2.26). While a decline was noted, the very wide confidence interval suggests that the study may have been underpowered for this endpoint. One prior study investigated the use of a similar strategy to ours in the Veterans Affairs Greater Los Angeles Healthcare System in men 75 years of age and older. In that study, the eligible population was 30,150 and the baseline screening rate was $8.3 \%$, much lower than the typical national rate, with a $30-40 \%$ decline during their intervention periods. ${ }^{9}$ This study, conducted in an academic center likely involving numerous trainees, does not address the generalizability of this intervention to a large community-based practice. As seen in Table 1, our eligible population was almost five times larger and our baseline screening rate was strikingly similar to national data, while our decline was a durable $58.5 \%$ after introduction of the BPA and the large temporal variation was diminished. Additionally, our system includes over 4000 primary care providers and a racially and ethnically diverse patient population.

\section{Strengths and Limitations}

Our study is unique in several respects. Our integrated healthcare system allows us to define an "eligible population" which served as the denominator in rate calculations; thus, accurate rates could be determined. Our sample size was quite large and diverse, and PSA screening rates were determined by the PSA test performed in the electronic medical record, not by patient recall or administrative claims data. In addition, this study involved a large number of hospitals and medical offices and several thousand care providers in community-based practice throughout a large geographic area. Because our design employed a simple, inexpensive BPA implementation only (with no warnings or educational aspects), we were able to study the effect of the BPA alone without the potential for contamination by cointerventions. We used an interrupted time series analysis which is widely considered to be the best methodology for evaluating the effectiveness of populationlevel health interventions that have been implemented at a clearly defined point in time when outcomes that are expected to change relatively quickly after the intervention are implemented. One limitation of our study was that this was not a randomized trial, yet the magnitude of the rate decline was large and sustained after the intervention. Another limitation of our study was that we did not conduct individual chart reviews to determine whether patients for whom the PSA was ordered had any symptoms suggestive of prostate cancer that would warrant testing. However, we suspect that only a small fraction of the men studied would be symptomatic and we have no reason to suspect that the distribution of symptomatic men would have changed in our population during the study period. This study took place in a consensus-driven integrated health plan and may not generalize to other practice settings.

\section{Conclusions}

Although PSA-based screening for prostate cancer remains controversial, most organizations recommend against routine PSA-based screening in men 70 years of age or older. Screening in the elderly may result in overdiagnosis and overtreatment along with numerous risks associated with these interventions. Inappropriate testing and the downstream consequences also result in a large financial burden to healthcare systems. Our intervention significantly reduced inappropriate testing in this population. This simple and inexpensive intervention is likely widely generalizable to many other healthcare systems and other clinical scenarios. Of course, issues such as "alert fatigue" and similar challenges must be considered to ensure effectiveness of similar practice-changing interventions. Future studies should measure patient and provider satisfaction and unintended consequences, such as less ordering in appropriate patients. However, our study illustrates the great potential of new electronic tools for helping providers deliver more appropriate, cost-effective care.

Corresponding Author: Joseph Presti, Jr, MD; Department of Urology, Kaiser Permanente Northern California, Oakland, CA, USA (e-mail: Joseph.c.presti@kp.org).

Funding Information The study was supported by The Permanente Medical Group Delivery Science and Physician Researcher Programs.

\section{Compliance with Ethical Standards:}

Conflict of Interest: The authors declare that they do not have a conflict of interest.

\section{REFERENCES}

1. Grossman DC, US Preventive Services Task Force. Screening for prostate cancer: US Preventive Services Task Force recommendation statement. JAMA. 2018;319(18): 1901-1913.

2. Gaseem A, Barry MJ, Denberg TD, Owens DK, Shekelle P, for the Clinical Guidelines Committee of the American College of Physicians. Screening for prostate cancer: A guidance statement from the Clinical Guidelines Committee of the American College of Physicians. Ann Intern Med. 2013;158(10):761-769.

3. Clinical Preventive Service Recommendation. Prostate cancer screening in men aged 70 and older. Available at: https://www.aafp.org/patientcare/clinical-recommendations/all/prostate-cancer.html. Accessed August 9, 2019

4. Carter HB, Albertsen PC, Barry MJ, et al. Early detection of prostate cancer: AUA Guideline. J Urol. 2013;190(2):419-426.

5. Schröder FH, Hugosson J, Roobol MJ, et al.. ERSPC Investigators. Screening and prostate cancer mortality: results of the European Randomised Study of Screening for Prostate Cancer (ERSPC) at 13 years of follow-up. Lancet. 2014;384(9959):2027-2035. 
6. Draisma G, Boer R, Otto SJ, et al. Lead times and overdetection due to prostate-specific antigen screening: Estimates form the European Randomized Study of Screening for Prostate Cancer. J Natl Cancer Inst. 2003;95:868-878.

7. HEDIS Measures and Technical Resources. Non-recommended PSAbased screening in older men. Available at: https://www.ncqa.org/ hedis/measures/non-recommended-psa-based-screening-in-older-men/ . Accessed August 9, 2019.

8. Bejjanki H, Mramba LK, Beal SG, et al. The role of a best practice alert in the electronic medical record in reducing repetitive lab tests. Clinicoecon Outcomes Res. 2018;10:611-618.

9. Shelton JB, Ochotorena L, Bennett C, et al. Reducing PSA-based Prostate Cancer Screening in Men Aged 75 Years and Older with the Use of Highly Specific Computerized Clinical Decision Support. J Gen Intern Med. 2015;30(8):1133-1139.

10. Bernal JL, Cummins S, Gasparrini A. Interrupted time series regression for the evaluation of public health interventions: a tutorial. Int $\mathrm{J}$ Epidemiol. 2017;46(1):348-355.

11. Moyer VA. US Preventive Services Task Force. Screening for prostate cancer: US Preventive Services Task Force recommendation statement. Ann Intern Med. 2012;157(2): 120-134.

12. US Department of Health and Human Services. Office of the Inspector General: Medicare Payments for Clinical Diagnostic Laboratory Tests in 2017: Year 4 of Baseline Data. Available at: https://oig.hhs.gov/oei/ reports/oei-09-18-00410.pdf. Accessed August 9, 2019.

13. Prostate Biopsies Reduced Once Again in Medicare Proposed Fees for 2018. Available at: https://apsmedbill.com/whitepapers/prostate- biopsies-reduced-once-again-medicare-proposed-fees-2018. Accessed August 9, 2019.

14. Walraven CV, Goel V, Chan B. Effect of population-based interventions on laboratory utilization - a time-series analysis. JAMA. 1998;280:20282033.

15. Lin CP, Payne TH, Nichol WP, Hoey PJ, Anderson CL, Gennari JH Evaluating Clinical Decision Support Systems: Monitoring CPOE Order Check Override Rates in the Department of Veterans Affairs Computerized Patient Record System. J Am Med Inform Assoc. 2008; 15:620-626.

16. Feldman LS, Shihab HM, Thiemann D, et al. Impact of Providing Fee Data on Laboratory Test Ordering A Controlled Clinical Trial. JAMA Intern Med. 2013;173(10):903-908.

17. Levick DL, Stern G, Meyerhoefer CD, Levick A, Pucklavage D. Reducing unnecessary testing in a CPOE system through implementation of a targeted CDS intervention. BMC Med Inform Decis Mak. 2013;13:43-49.

18. Najafi N, Cucina R, Pierre B, Khanna R. Assessment of a targeted electronic health record intervention to reduce telemetry duration: a cluster-randomized clinical trial. JAMA Intern Med. 2018;179(1):11-15.

Publisher's Note Springer Nature remains neutral with regard to jurisdictional claims in published maps and institutional affiliations. 